\title{
B. F. SKINNER'S RADICAL BEHAVIORISM: HISTORICAL MISCONSTRUCTIONS AND GROUNDS FOR FEMINIST RECONSTRUCTIONS
}

\author{
Maria R. Ruiz \\ Rollins College
}

\begin{abstract}
Feminist critiques of traditional psychological approaches have generated thorough feminist revisions most notably in psychoanalytic and developmental theory. Although behaviorism has attracted strong objections from feminist critics, claims of its antithetical positioning vis-a-vis feminist theory construction have practically remained unchallenged. A preliminary step in formulating 'grounds for a synthesis is to clarify the multiple meanings of behaviorism. Specifically, the fusion of Watson's methodological behaviorism and Skinner's radical behaviorism in the literature must be disentangled in order to address the latter's potential as a conceptual framework for constructing feminist theory. Key conceptual features of radical behaviorism that suggest its potential as a vehicle for building a feminist epistemology include: radical behaviorism's contextualistic world view, its interpretation of agency, its treatment of private experience and self knowledge, and its understanding of the pivotal functions of the verbal community.
\end{abstract}

The growing impact of feminist scholarship across disciplines has forced psychology to address critiques that point to the limitations of traditional psychological approaches and call for feminist alternatives. Behaviorism, with its historical roots in logical positivism, is among those traditional models that have attracted some of the strongest objections by feminist critics (e.g. Kaschak; 1992, Unger, 1989). The spirit of these objections is concisely captured in Unger's (1988) reflection that "The juxtaposition of the words 'behaviorism' and 'the study of women' seems to some of us to be a contradiction in terms" (p. 125). But unlike other models that have also been targeted for feminist revisions, such as psychoanalysis (e.g. Chodorow, 1978; Flax, 1978; Keller, 1985) and developmental theory (e.g. Burman, 1992; Gilligan, 1982), the claims of behaviorism's antithetical positioning vis a vis feminist research and theory construction have, for all practical purposes, remained unchallenged. A notable exception has been the work by Lott (1990, 1991) and Lott and Maluso (1993), which presents a persuasive arguement for the compatibility of social learning theory and feminist psychology.

The first step in formulating grounds for a synthesis between contemporary behaviorism and feminist scholarship is to recognize that behaviorism is not a monolithic psychological model, and begin to disentangle the multiple meanings that obscure the boundaries of individual behavioral models subsumed under the generic

\section{AUTHOR'S NOTE:}

This manuscript was originally published in Psychology of Women Quarterly, 19 (1995), 161-179. Reprinted with the permission of Cambridge University Press. I thank Judy Kinnie and Nan Mitchell for their help in the preparation of this manuscript. Address correspondence and reprint requests to: Maria R. Ruiz, Department of Psychology, Rollins College, Winter Park, FL 32789. 
heading. This preliminary step is necessary in order to bring to the fore the particularities of radical behaviorism, and to address its potential as a conceptual framework for feminist psychological theory construction.

\section{Radical Behaviorism: Historical Misconstructions}

For those of us who associate names with ideas, the name B.F. Skinner will almost certainly come to mind in discussions of behaviorism. This is true even though, as Morris (1988) has documented, Skinner's radical behaviorism began to take a dominant position within the psychological literature, including textbooks, only in the late 1950's. Various other behavioral models preceded and coexisted with Skinner's, including those of Hull (1935, 1937), Spence(1956, 1960), Tolman(1922, 1932), and of course the model developed by the founder of the school of behaviorism in Psychology, John B. Watson (1913, 1919). Skinner articulated the tenets of radical behaviorism in many different writings through the years (e.g. 1953, 1959, 1969, 1974,1978), and eventually complained at having to readdress misconstructions in the literature (Skinner, 1984). Nonetheless, there is a tendency to view behaviorism as a monolithic psychological model. Features of that model that are strongly criticized in the psychological literature and beyond thus have become inappropriately ascribed to radical behaviorism. As a result Skinner's version becomes misconstructed as the contemporary embodidment of objective "black box" psychology (Iversen, 1992).

Any attempt to disentangle radical behaviorism from other behaviorisms must focus on the conceptual distinctions between it and Watson's $(1913,1919)$ classical behaviorism, which was developed and popularized during the first two decades of this century (also referred to as methodological behaviorism). Although Skinner (1974) himself specifically addressed these distinctions, extensive reviews of textbooks and critiques of Skinner's work by Todd and Morris $(1983,1992)$ reveal that the misconstructions of radical behaviorism as methodological behaviorism are widespread. These authors described a series of common misconstructions and contended that these are passed down through "academic folklore." These misconstructions maintain, for example, that radical behaviorism: (a) is a mechanistic stimulus-response psychology; (b) is primarily concerned with the behavior of small organisms in experimental chambers; (c) conceptualizes the organism as a passive recipient of external forces; ( d) denies or ignores innate contributions to behavior in its extreme environmentalism; (e) requires that we fragment behavior down to elemental units for analysis; and (f) deals only with overt behavior and so denies or ignores subjective experience such as feelings and thought.

Indeed, from a feminist perspective, these characterizations, if accurate, would suggest irreconcilable differences between radical behaviorism and feminism with respect to core assumptions about the nature of the human. Any argument in support of a synthesis might well be characterized as misguided. These points will be the focus of a later section, however, let us consider the conceptual framework of radical behaviorism in contrast to that of methodological behaviorism. To organize the discussion, I will address the conceptual categories in each system that give shape to what philosopher Stephen C. Pepper (1942) referred to as the "world hypothesis" or 


\section{B. F. SKINNER'S RADICAL BEHAVIORISM}

world view which underlies each model. This discussion will identify discrepancies in the respective views on human behavior, the nature of scientific knowledge, and the purposes of science. In so doing, I will also highlight the differences in Watson's and Skinner's views on the proper methods of scientific research which follow from their conceptual categories.

\section{Methodological Behaviorism and Mechanism}

Watson's Methodological Behaviorism was a direct outgrowth of logical positivism. In his search for positive truth in psychological research, Watson ruled consciousness out of the realm of scientific research, as its structure can never be directly and objectively observed. Methodological behaviorism did not fully resolve the mind-body problem, however, because Watson still presumed mind to exist, albeit outside the realm of scientific psychology (for a discussion of methodological behaviorism and mentalism see Day, 1992b). What Watson did include in the realm of scientific inquiry were essentialist stimulus-response units (Palmer \& Donahoe, 1992). These units were defined by formal operational definitions that he assumed comprised fundamental elements of behavior-environment interactions.

In methodological behaviorism, causal relationships between stimulus and response are established through temporal contiguity, and the process is viewed as one of linear causation from stimulus to response. The characterization of the responsive organism (Baer, 1976) as recipient of external stimulation and reactive to it is accurate in methodological behaviorism. Watson's efforts to rid scientific psychology of mentalistic agency translated into an extreme environmentalism that has been emphasized in the literature, in spite, as Skinner (1974) and others (Todd \& Morris, 1992) have noted, of Watson's frequent discussions of the role of heredity in behavior (e.g., Watson, 1919, 1927, 1930).

Watson's behavioral model is most accurately characterized as mechanistic in its world view (Carr, 1993; Morris, 1988, 1993a), following Pepper's categories. Mechanism as a world view assumes that the whole organism is reducible to its parts. The root metaphor in mechanism is The Machine, and in Watson's conceptual model the behaving organism was assumed to function according to discrete and independently analyzable parts. In other words, the parts of the organism are assumed to exist independently of their relationship to other parts, and thus the model is reductionistic and molecular, and fragments pieces of experience into isolated analyses. Pepper (1942) explained these mechanistic concepts:

A whole is nothing but an aggregation of parts, or at most a spatial configuration. Name the parts and their position relative to one another, and state the laws by which these parts moved into their present postions from previous positions, and the task of description is completed. Whether the parts be sensations, images, and feelings goverened by a laws of association, or physiological reactions governed by a law of conditioned reflex, makes no fundamental difference in the mode of conception, (p. 111)

Watson's epistemological stance was consistent with naive realism as well as the mechanistic world view in that the knower (i.e.. the scientist), and the known, (i.e.. subject of observation) occupy separate and distinct spheres. The scientist who seeks objective truth knows, not the world itself, but only a copy of it. The criterion for true and valid knowledge in methodological behaviorism is, therefore, a matter of 


\section{RUIZ}

how well the copy known by the scientist corresponds to the real world. Such correspondence is determined indirectly by evaluating correspondence among copies received by independent knowers.

\section{Radical Behaviorism and Contextualism}

In contrast to methodological behaviorism, Skinner's Radical Behaviorism is contextualistic in its worldview, again following Pepper's categories ( Morris, 1988, 1993a, 1993b; Hayes, Hayes, \& Reese, 1988). The root metaphor of contextualism is "The Ongoing Act in Context" or "The Historical Act," and the meaning of behavior in the present context derives from past contexts and personal history. In contextualism, an act out of context has no meaning, and is therefore categorically not an act.

For the contextualist, the whole organism is basic and primary, and its parts are derived. The parts therefore cannot be meaningfully analyzed independently because their very nature is relational and meaningful only with respect to other parts within the whole. Hayes, Hayes, and Reese (1988) have discussed Skinner's conceptualization of the operant and its adherence to a contextualistic worldview. Operants are functional classes of behavior which are related to functional classes of stimulus events in the environment. Operants have no fixed boundaries, and are characterized by topographical variability. That is, members of a functional class have common effects on the environment. Those effects, not the formal properties of the members of the class, define the operant class. Hence responses that look quite different, such as holding a clinched fist to another's face and an admonition spoken in the manner of a joke, may both qualify as members of a class of aggressively threatening operants, for example, if they result in an adversary withdrawing from an offensive posture.

The essentialist nature of mechanistic behavioral units in methodological behaviorism is thus replaced by fluid and variable behavioral units that emerge through environmental selection. Chiesa (1992) emphasizes this as an important distinction between radical and methodological behaviorism because selection allows for the emergence of novel forms of behavior in Skinner's system, whereas essentialistic units of behavior are nontransformative in Watson's mechanistic model.

Cause-effect relationships requiring temporal contiguity between stimuli and responses in methodological behaviorism give way to what Morris (1988) called "an integrated-field perspective of functional interdependencies" (p. 303) in radical behaviorism. Therefore behavior and environmental events that are temporally distant can be functionally interrelated, as is the case when long-deferred consequences lead to useful rules (Skinner, 1957, 1969). A crucial component of the integrated field is the scientist, and Skinner's epistemological position is consistent with Pepper's notion that in contextualism, the scientist cannot stand apart from the world that is known, but is rather a part of that world. Skinner (1974) talked about it this way:

It would be absurd for the behaviorist to contend that he is in any way exempt from his analysis. He cannot step out of the causal stream and observe behavior from some special point of vantage, "perched on the epicycle of Mercury." In the very act of analyzing human behavior he is behaving-as in the very act of analyzing thinking, the 


\section{B. F. SKINNER'S RADICAL BEHAVIORISM}

philosopher is thinking. (p. 234)

Radical behaviorist epistemology has a phenomenological quality, as Morris (1988) noted, that belies the mechanistic distinction between the knower and the known. In fact, Day (1992a) stresses that it is Skinner's epistemological stance that most distinctly separates his philosophical position from the logical positivist tradition. Day (1992a, p. 48) explains that this "epistemological cleavage" leads to two entirely different views on operational definitions. For the methodological behaviorist, the meaning of a psychological term is given in its operational definition, and by extension, so is its separate reality. That is, once the scientist has named the psychological process, and correspondence is established within the scientific verbal community, the process is assumed to exist independently of the scientist. For Skinner, on the other hand, operational definitions refer to aspects of the scientist's verbal behavior, and thus are relational terms between the scientist and the subject of inquiry.

It is likewise Skinner's epistemological stance that most clearly aligns radical behaviorism with the pragmatist philosophy of William James (Baum, 1994; Day, 1992b; Morris, 1993a). For James, all knowledge is basically functional in nature, and our capacities for knowledge are driven by the practical needs to adapt to our environments. For Skinner, knowledge is action, and "knowing" refers to behavioral relations in context that facilitate adaptation. For Skinner, as for James, the truth criterion or method for defining truth and value is "successful working," or as the behaviorist puts it "effective action" (Skinner, 1974, p. 235). Scientific beliefs about reality are therefore true only if they allow the scientist to function successfully with respect to particular goals (O'Donnell, 1985). Science, in turn, is defined as the activity of scientists, and the knowledge uncovered through this activity is meaningful only relative to its context. "Knowing" is a behavioral relation (Morris, 1993a) influenced by the knower's historical and present contexts. Thus for Skinner, ultimate knowledge is categorically meaningless since it is by definition context free.

When one examines methodological behaviorism and radical behaviorism from an epistemological stance, two distictively different views on the goals of science emerge. The purpose of methodological behaviorism is to distill objectified universal truths from the subject of inquiry, or, in Watson's (1924) words:

behavioristic psychology has as its goal to be able, given the stimulus, to predict the response-or, seeing the reaction take place to state what the stimulus is that has called out the reaction (p. 18)

Radical behaviorism, on the other hand, seeks to understand and describe dynamic workings and the emergent meaning of behavior within a particular place and time. In speaking of how we can come to know an operant class, Skinner (1969) contrasts the two traditions:

An operant is a class, of which a response is an instance or member. [and] ...a set of contingencies defines an operant...A response is reinforced in the presence of a given stimulus, but we cannot tell from a single instance ... the contingencies.... Only by surveying many instances can we identify ...the contingencies. This is not quite the traditional question of whether we can know particulars or universals, but it is interesting that the practice of imparting a universal meaning to the response itself as an alternative to surveying a large number of instances is close to the Platonic practice of letting ideas stand for universals. (p. 131-132)

A core issue in Skinner's epistemological stance that unequivocally separates 
radical behaviorism from Watson's methodological behaviorism is Skinner's position on private events. While Skinner (1974) outright dismisses dualism and mentalism, which attribute independent causal agency to the mind and its derivatives, he madehis position on private events such as feelings and thought equally clear as he pointed out:

A science of behavior must consider the place of private stimuli as physical things, and in doing so it provides an alternative account of mental life. [The question he raises then is] What is inside the Skin and how do we know it? [He goes on to say] The answer is, I believe, the heart of Radical Behaviorism ( p. 211-212).

In the same text, Skinner (1974) summarized his position on consciousness and subjective reality by way of contrasting it with the position taken by Watson in methodological behaviorism:

Methodological Behaviorism and certain versions of logical positivism could be said to ignore consciousness, feelings and states of mind, but Radical Behaviorism does not thus "behead the organism"; it does not "sweep the problem of subjectivity under the rug"; it does not "maintain a strictly behavioristic methodology by treating reports of introspection merely as verbal behavior"; and it was not designed to "permit consciousness to atrophy." (p 219)

In dismissing the distinction between objective and subjective reality, Skinner reconceptualizes the problem of privacy. Although there is no question that private events exist, and that they are important, the central challenge to him is to determine how it is that we come to have knowledge about them. This philosophical question is then given psychological treatment by Skinner who viewed the social environment, specifically, the verbal community as the key. The verbal community is that portion of our culture, or social environment, that formulates and preserves the language that symbols the culture uses to express abstract thinking and to transmit its cultural practices to the next generation. For Skinner, the central problem is how the verbal community, which has access only to public events, teaches us to communicate effectively under the control of stimulating conditions that occur privately, or within the skin. In essence, Skinner argued that our communicated knowledge of private events is socially constructed through the verbal community. The fact that Skinner (1974) refers to this analysis as the "heart of Radical Behaviorism" reflects the centrality of private experience and subjective reality among the core issues in radical behaviorism (p. 212).

\section{Radical Behaviorism: Grounds for Feminist Reconstructions}

My attempt in this overview of the conceptual framework of radical behaviorism has been to sketch out the central and defining characteristics of Skinner's thinking with respect to human behavior, the nature of scientific knowledge and the purposes of science. Although this articlee is certainly not intended to be a detailed account, I have touched upon those issues that I think are most crucial in formulating grounds for a synthesis of radical behaviorism and feminist theory and research. But before attempting to formulate such grounds, we might well ask the question "is it really worthwhile doing so?" Many feminist scholars have argued that to develop a truly feminist theoretical and research program, we must break with the old, and start from ground zero. We must discard conceptual paradigms and theories that are the 


\section{B. F. SKINNER'S RADICAL BEHAVIORISM}

products of the traditional masculinist orientation in order to discover what a true feminist alternative account might be about.

It seems to me that while "fresh start" approaches may provide one alternative, it may be equally important to reflect upon those traditions within which our own intellectual development took form, and which have contributed to productive, as well as the repressive, outcomes that have inspired feminist resistance. Engaging in historical reflection from a feminist perspective, however, requires that we go beyond constructed historical accounts that provide a distorted history of our intellectual traditions (O'Connell \& Russo, 1991). Writing within the growing perspective of "women's history in psychology," Russo \& Denmark (1987) reminded us that "The contributions of women psychologists have been largely unrecognized, undervalued, and invisible in historical accounts" (p. 279). Such accounts, therefore, undermine the rich historical contexts and contributions of feminist psychological scholarship (see, e.g., Furumoto \& Scarborough, 1986; Russo \& O'Connell, 1980), and would encourage us to construe contemporary feminist psychology as an ahistorical, isolated event within the history of the discipline. Commenting on the advantages of reflection for contemporary feminist psychology Erica Burman (1992) suggested that:

We can at least try to operate within a theoretical framework which could permit the elements for an alternative conception of subjectivity to emerge... [while helping to guard against a] total interpretive relativism... [that may result from ] throwing all models and theories into question (p. 50-51).

What then can radical behaviorism offer feninist psychological scholarship in its aim to analyze and transform the subordination of women by decentering the masculinist perspective? Does radical behaviorism suggest itself as a cohesive and conceptually compatible framework for the feminist challenge to traditionally prescribed "norms"? And finally, can the radical behaviorist framework help advance a feminist epistemology grounded in the experiences of women and those of other marginalized groups? I believe that radical behaviorism, far from being an irreconcilable foe, actually offers a framework for understanding human nature that can prove useful to the feminist agenda in the following ways.

First, radical behaviorism's appeal for a contextual understanding of the human condition finds audible resonance in the feminist literature. In fact, one of the strongest objections to psychological frameworks and derivative models that have received popular acclaim and widespread consumption, such as co-dependency, is the personalization of problems that have their origins in socio-political structures. Countless feminist critics have echoed Celia Kitzinger's conclusion (Hall, Kitzinger, Loulan, \& Perkins, 1992) that:

Psychology has nothing to offer feminism. It's destroying our politics by translating the political map into the personal, by offering individualized language which focuses on the private inner life instead of the public external world of oppression [and] dismissing someone's political opinions on the grounds of their alleged personal pathology. (p. 9-10)

Although feminists would be well advised to resist psychological models grounded in abstract individualism, we must also resist the lure to sweepingly dismiss an entire discipline, and with it, discard potentially useful disciplinary tools that can be instrumental in constructing alternative models compatible with feminist values. Skinner's view of human behavior as ongoing acts in context is a case in point. This 


\section{RUIZ}

view categorically rejects any attempt to understand human action outside of the boundaries of personal life experience and current circumstance, as the meanings of acts are circumscribed by contexts in one's life history.

Although feminist scholars would confirm the importance of context in understanding an individual's acts and knowledge base, one concern that this conceptualization poses is the issue of agency. If the locus of meaning is external to the individual, how can we expect individual resistance to be initiated? That is, how might we expect a disempowered individual to be the agent of change with respect to the very dominant cultural practices that create her disempowerment? To begin to answer this question, we must look to Skinner's views on the nature of the individual's reciprocal interdependency with her context, which is quite distinct from the essentialist and nontransformative characterization of individual behavior found in methodological behaviorism.

Skinner viewed the reciprocal interdependency between the individual and her context as the key to creating and changing cultural practices. Skinner's active organism is acted upon while simultaneously acting upon external circumstances. Although Skinner ruled out the existence of a dualistic autonomous agent initiating action from within and in a context-free fashion, cultural practices are human creations and products of individual and collective human action. In this sense Skinner (1971) wrote that although the individual may seem particularly vulnerable, "Man [sic] has 'controlled his own destiny'...The man that man has made is the product of the culture man has devised" (p. 208).

A feminist quoting from this text must pause to reflect on Skinner's language, even at the risk of momentarily segmenting the central discussion. Skinner's language conveys more than what I assume to be his intended meaning. That is, as humans we are responsible for our destinies in that we exert reciprocal control over the environmental contingencies that in turn operate in behavioral selection. But his exclusionary equation of "man" with "human" also conveys what I assume to be unintended meaning in the discourse, and reflects the practice noted by Lerner (1986) that as women we "have had to express ourselves through patriachal thought as reflected in...a language in which we are subsumed under the male pronoun and in which the generic terms for 'human' is 'male'" (p. 232). As such, our exclusionary language credits man as sole architect of cultural design and obscures the fact that "Women are and have been central, not marginal, to the making of society and to the building of civilization" (p. 4).

How, then, does the suppressed voice of woman come to the forefront of cultural reform? In answering this question, we must look at the radical behaviorist's reconceptualization of agency, the second point I want to raise as a possible point of juncture for convergence between radical behaviorism and feminist psychological theory construction. Zuriff's (1985) threefold criterion is helpful in clarifying the radical behaviorist's perspective on agency. An act may be said to be the intelligent act of an agent: (a) if it is purposeful in the sense that it is the result of a long history of learning (that is, purpose here refers to historical contingencies, not futuristic expectations), and it is performed under appropriate stimulus conditions; (b) if the specific act is one of many possible manifestations of a disposition acquired through that history, and (c) if the agent is able to give an explanation for the act in the 


\section{B. F. SKINNER'S RADICAL BEHAVIORISM}

current context. That is, the agent does not simply "know how" with respect to the act, as this would demonstrate automaticism. The agent also "knows that" with respect to the act and can explain the context that sets the conditions for the act as well as its functions. So, to speak of a radical behavioristic understanding of agency is to speak of an act that is embedded in a system of relationships with the current and historical contexts, and for which the agent is able to describe such relationships.

Given this re-conceptualization of agency, how would the radical behaviorist view the origins of resistance by marginalized individuals? To answer this question we must return to the locus of agency that requires a history of learning (or experiential history) that enables us to "know how," and a symbolic or verbal repertoire that enables us to "know that" (i.e., to explain an act of resistance and its functional relation to external, contextual circumstances). But here, the critical tool in the formulation and articulation of such explanations from a radical behavioristic perspective, is the verbal community, whose members teach us how to represent experience symbolically through its language practices.

We might say, using everyday language, that "knowing how" does not necessarily require a conscious awareness of the key aspects of the current circumstance that set the occasion for our actions. That is, one may know how to respond in a particular way under certain circumstances because it "feels" like the right thing to do, but not be able to explain why one does so beyond stating one's feelings. Such conscious awareness is, on the other hand, a necessary condition for "knowing that" we are acting in relation to key aspects of the current circumstance. In other words, "knowing that" about an act requires making the connection that a publicly observable act, along with the corresponding privately experienced events (including feelings and thoughts), are functionally interrelated with key aspects of the current context that set the occasion for both. In this sense, Zuriff's (1985) process of "knowing that," a critical feature of agent acts, is closely related to Skinner's process of self-knowledge, the development of which is mediated by others within the individual's verbal community.

For Skinner, self knowledge is a process that originates in our social transactions with the verbal community. Skinner (1974) put it this way:

Self knowledge is of social origin. It is only when a person's private world becomes important to others that it is made important to him. It then enters into the control of the behavior called knowing. But self knowledge has a special value to the individual himself. A person who has been made "aware of himself" by the questions he has been asked is in a better position to predict and control his own behavior. (p. 31)

The critical role played by the verbal community in an individual's acquisition of self knowledge in radical behaviorism brings us to a third important juncture where the latter may serve as a useful conceptual tool for the construction of feminist psychological theory.

A central concern in the feminist agenda is the development of a feminist epistemology through which we can uncover subjective truths as spoken through the voices of women. Social and political institutions have historically silenced women's voices and have imposed on women a patriarchal vision of reality that services and nurtures standard cultural practices. As we know, traditional psychological theory and research practices have complemented the work of other institutions in creating 
an effective silencing process. And psychology has done so by creating exclusive male-based psychological standards, and interpreting "difference" as either substandard or pathological, thus impacting a wide range of psychological theories and practices (e.g. Gilbert \& Osipow, 1991; Jacklin \& McBride, 1991; Lewin \& Wild, 1991; Lott, 1991; Maracek \& Hare-Mustin, 1991; Travis, Gressley, \& Crumpler, 1991) Psychology has also contributed to the silencing process through its exclusionary professional practices that have historically muffled the voices of women scientists (see Furumoto, 1988; Morawski \& Agronik, 1991; Russo \& Denmark, 1987).

Feminist critics have spelled out the problematic nature of the forms of knowledge and the ensuing realities represented by the prevailing masculinist epistemologies that are the foundation of traditional psychological models (Aebischer, 1988; Banaji, 1993; Hare-Mustin \& Marecek, 1990; Kaschak, 1992; Morawski, 1990; Unger, 1986). The assumption that the rules of evidence in scientific empiricism, including the detached relationship between the knower and the known, are sufficient to discover objective value-free "facts" has been dismantled by cogent feminist analyses (e.g. Crawford, 1989; Crawford \& Marecek, 1989; Sherif, 1979; Unger, 1988). These demonstrate that the knowledge we create through scientific inquiry is relative, contextual, complex and subjective (Unger, 1983). It is also value-laden, as is the very process of inquiry.

Commenting on modern science in general, Keller (1985) has exposed the invisible yet pervasive impact of gender ideology on our scientific knowledge base and its masculinist perspective. Feminist writers have responded with a call for "women-specific" knowledge (Aebischer, 1988), or feminist standpoint epistemologies (Harding, 1986), which recognize women's experiences as distinctively crucial to the development of alternatives. The essential features of feminist epistemology include placing women at the center of inquiry, reducing or eliminating the boundary between the knower and the known, employing knowledge to defy and challenge the subordination of women, as well as a commitment to creating an understanding of other categories of oppressed experience including class, race and ethnicity (Fee, 1986). Above all, feminist epistemology adopts a posture that contrasts sharply with its masculinist counterpart, and which in Keller's (1985) words "allow[s] one to 'listen to the material' rather than assuming the scientific data self-evidently 'speak for themselves'" (p. 134).

Keller reminds us that the problem with this assumption "is, of course, that data never do speak for themselves...[and] all data presuppose interpretation" (p. 130). Historically, interpretation of psychological data, including data from and about women, has been undertaken from a masculinist perspective, and the contributions of feminist psychologists, which are virtually as old as the discipline itself (e.g. Calkins, 1986; Hollingworth, 1914, 1916; Thompson, 1903), have been neglected. The dominant masculinist discourse in psychology, therefore, has historically overshadowed feminist discourse. Although neglect and overshadowing have had a disempowering effect, the particularities of women's experiences have found increasing support in the last three decades with the growing salience of the feminist verbal community. Consequently, a psychological language through which women can express context-anchored meaning is now emerging. 


\section{B. F. SKINNER'S RADICAL BEHAVIORISM}

A radical behaviorist would argue that a necessary condition for the development of such a language by women is the existence of a verbal community for whom the private worlds of women are important and which asks the right kinds of questions about those worlds. To Skinner, the right kinds of questions about our private worlds are ones that enable us to ground our feelings in the circumstances of our lives. Our culture's traditional belief in personal autonomy and independent agency, Skinner (1974) wrote, has led our verbal community at large to ask questions about our private worlds which focus on feelings, to the near exclusion of contextual circumstances. "The verbal community asks, 'How do you feel?' rather than 'Why do you feel that way?'...It has not, until recently, induced people to examine the external conditions under which they live" (p. 170).

A verbal community that values women's personal experiences and that asks the right kinds of questions about those experiences can, to borrow Skinner's expression, enable a woman to "become aware of herself" and thus begin to uncover the multiplicity of meanings embedded in women's lives. This is in fact one of the important functions performed by our feminist verbal community. Women's studies conferences and journals such as the Psychology of Women Quarterly are indeed excellent examples of a portion of that community coming together to perform precisely that function. That is, of creating a context through which a collective verbal repertoire of shared experiences can emerge and be sharpened.

\section{Feminist Reconstructions of Radical Behaviorism}

There are three related questions that I would like to raise at the start in addressing feminist radical behaviorism. First, what would it mean for feminist psychologists to adopt a radical behavioristic conceptual framework, and how could such an adoption work to further the goals of a ferminist research agenda? Second, what might such a synthesis look like? And third, what kinds of research questions would a feminist perspective bring into focus in behavior analysis?

Complete answers to these questions will have to be developed inductively through direct research efforts by feminist behavior analysts. I offer here just a few ideas to begin the process. Although historically the radical behaviorist community has not had much input into the research literature on gender issues, radical behaviorists have a theoretical interest in behavioral variability and in describing the contextual conditions that influence the variation of behavior at the individual level. The conceptualization of the human that derives from this framework, and the theoretical premises and methods of investigation in operant learning theory suggest themselves as useful tools for the analysis of gender as well as other categories of experience such as race and class, which have significant impact on people's lives in a wide variety of ways. For example, the understanding of self knowledge as socially constructed, and the focus of analysis on the contingencies set up by the verbal community in the development of self knowledge may provide us with valuable insights into the establishment and transmission of gender as an "epistemological system," to borrow Kaschak's (1992, p. 35) characterization. Such analyses could help uncover the subjective meanings that women's experiences hold as we provide, within the research context, a feminist verbal community that is 


\section{RUIZ}

interested in women's private experiences and that asks the right questions about those experiences. Thus the radical behaviorist framework may prove valuable in the development of the type of feminist epistemology called for by so many feminist writers.

Similarly, a feminist perspective also has much to offer research programs within the field of behavior analysis. For example, one reason why behavior analytic research in the radical behavioral tradition often appears mechanistic is related to the pragmatic goal orientation of "successful working," or "effective action," which influences the types of research questions that tend to be asked, as well as the selection of behavioral units for analysis. Thus behavioral units reported in the literature frequently appear narrow and restricted, even though the operant unit can conceivably encompass complex forms of behavior. The analyses, in turn, can appear highly specific and molecular.

A feminist perspective brought to bear on behavior analytic research commits the scientist to a pragmatic goal orientation that is reflexive and contextual. That is, it forces the scientist to self-consciously consider the units of behavior selected for analysis, as well as the goals of the analysis, in light of their implications within the broader cultural context. Similarly, it encourages the scientist to reexamine the truth criterion of "effective action" and the method for establishing the validity of scientific beliefs in behavior analysis. These prescribe that scientific beliefs about reality are true only if they allow the scientist to function effectively with respect to particular goals.

A reexamination of this truth criterion must raise questions about the task of defining "effective action"and the cultural values reflected in those definitions. The rules of evidence in scientific empiricism do not provide answers to these questions because they explicitly authorize and privilege the scientist as sole arbiter. But the feminist call for reflexivity in our scientific practices is nowhere more critical, or the process of scientific inquiry more value-laden, than it is during this initial stage as we conceptualize our research questions. And although communal consensus is not a logical requirement in establishing the scientific validity of pragmatic truth, a feminist approach that seeks to transform values demands the scientist converge on the task not as a lone decontextualized player, but as a community-conscious member of a culture whose values are reflected in its cultural practices, including the practice of science. These questions of values take on particularly important meanings for those of us conducting research in psychotherapeutic and educational settings.

We must not lose sight of the fact that scientists are an integral part of our culture, and we contribute to it directly in the very act of formulating scientific questions and in evaluating and selecting from possible solutions (Gergen, 1988). Therefore, we must also ask, what cultural practices are we selecting for and substantiating within our research efforts? And, who benefits? Skinner (1971) believed that cultural practices evolve if they add to the long-term survival of the culture when:

A given culture evolves as new practices arise, possibly for irrelevant reasons, and are selected by their contribution to the strength of the culture as it "competes" with the physical environment and with other cultures. A major step is the emergence of practices which induce members to work for the survival of their culture...[so that] the 


\section{B. F. SKINNER'S RADICAL BEHAVIORISM}

evolution of a culture introduces an additional kind of good or value. A culture which for any reason induces its members to work for its survival is more likely to survive. (p.143-144)

The feminist behavior analyst, however, must not accept the evolution of cultural practices through selection by survival contingencies as axiomatic. A patriarchal society that subordinates and marginalizes large groups of people may indeed survive, but survival alone is not an acceptable value. In the long run, the stability of a culture depends on the satisfaction of its members, and Skinner cautioned that "A culture needs the support of its members, and it must provide for the pursuit and achievement of happiness if it is to prevent disaffection or defection" (p. 152).

Skinner also noted that cultural change is inevitable, and he viewed unquestioned adherence to tradition as a threat to progress:

A culture must be reasonably stable, but it must also change, and it will presumably be strongest if it can avoid excessive respect for tradition and fear of novelty on the one hand and excessive rapid change on the other. Lastly, a culture will have a special measure of survival value if it encourages members to examine its practices and to experiment with new ones. (p. 152-153)

In the final analysis, a culture which supports pluralism and encourages diversity in its cultural practices will maximize its ability to acommodate to change and promote stable progress.

Although Skinner contended that "the survival of a culture functions as a value," he also warned of practices that can threaten a culture's stability and its future contributions, so that "Those who have been induced to work for their culture need to foresee some of the problems to be solved" (p. 182). The key to insuring cultural practices for the long term good of all, according to Skinner, is through cultural design which relies on countercontrol, or to put it in different terms, resistance. Yet he clearly understood the challenges this posed "The great problem [in cultural design] is to arrange effective countercontrol" (p. 171). In fact, fundamental cultural re-form resulting from countercontrol or resistance can only come about through the acts of agents who can at once explain and challenge not only the obvious, but the subtle cultural practices that deny women and other marginalized groups a voice in cultural design.

Feminist behavioral researchers can begin to contribute significantly to such resistance, first, by calling into question the immediate aims of their research programs with respect to the cultural practices, explicitly or implicitly supported by their research. Secondly, feminists can contribute by creating the verbal contingencies necessary for the disclosure of hidden unarticulated meanings received by those who have been excluded from the design of our cultural practices and whose lives are subordinated and oppressed by those very practices. Finally, feminist behavioral researchers can function as agents of change in cultural design by promoting inclusive practices which are, as Comas-Diaz (1991) advocates, informed by individuals who are outside the mainstream of society and whose personal identities are influenced by the interactive impact of gender and other critical categories of experience such as race, class, and ethnicity. A feminist influence on cultural design will ultimately require transforming the foundations of our knowledge by incorporating pluralism as a value. As agents.of change who promote diversity in our 
cultural practices, feminist behavioral researchers can serve the collective self interest and thus contribute to the long-term stability, strength, and progress of our culture as a whole.

\section{REFERENCES}

Aebischer, V. (1988). Knowledge as a result of conflicting intergroup relations. In M. M. Gergen (Ed.), Feminist thought and the structure of knowledge (pp. 142-151). New York: University Press.

Baer, D.M. (1976). The organism as host. Human Development, 19, 87-98. http://dx.doi.org/10.1159/000271519

Banaji, M.R., (1993). The psychology of gender: A perspective on perspectives. In A.E. Beall \& R.J. Sternberg (Eds.), The psychology of gender (pp. 251-273). New York: Guilford Press.

Baum, W.M. (1994). Understanding behaviorism-Science behavior and culture. New York: Harper Collins.

Burman, E. (1992). Feminism and discourse in developmental psychology: Power, subjectivity and interpretation. Feminism and Psychology, 2, 45-59. http://dx.doi.org/10.1177/0959353592021004

Calkins, M.W. (1986). Community of ideas of men and women. Psychological Review, 3, 426-430. http://dx.doi.org/10.1037/h0064618

Carr, E.G. (1993). Behavior analysis is not ultimately about behavior. The Behavior Analyst, 16, 47-49.

Chiesa, M. (1992). Radical behaviorism and scientific frameworks. American Psychologist, 47, 1287-1311. http://dx.doi.org/10.1037/0003-066X.47.11.1287

Chodorow, N. (1978) The reproduction of mothering: Psychoanalysis and the sociology of gender. University of California Press, Berkeley.

Comas-Diaz, L. (1991). Feminism and diversity in psychology: The case of women of color. Psychology of Women Qurterly, 15, 597-609. http://dx.doi.org/10.1111/j.1471-6402.1991.tb00433.x

Crawford, M. (1989). Agreeing to differ: Feminist epistemologies and women's ways of knowing, In M. Crawford \& M. Gentry (Eds.), Gender and thought (pp. 128-145). New York: Springer-Verlag.

Crawford, M., \& Maracek, J. (1989). Psychology reconstructs the female, 1968-1988. Psychology of Women Quarterly, 13, 147-165. http://dx.doi.org/10.1111/j.1471-6402.1989.tb00993.x

Day, W. (1992a). The historical antecedents of contemporary behaviorism. In S. Leigland (Ed.), Radical behaviorism: Willard Day on psychology and philosophy (pp. 13-58). Reno, Nevada, Context Press.

Day, W. (1992b). On the difference between radical and methodological behaviorism. In S. Leigland (Ed.), Radical behaviorism: Willard Day on psychology and philosophy (pp. 61-71). Reno, Nevada, Context Press.

Fee, E. (1986). Critiques of modern science: The relationship of feminism to other radical epistemologies. In R. Bleier (Ed.), Feminist approaches to science (pp. 42-56). New York: Pergamon.

Flax, J. (1978). The conflict between nurturance and autonomy in mother-daughter relationships and within feminism. Feminist Studies, 4, 171-189. http://dx.doi.org/10.2307/3177468

Furumoto, L. (1988). Mary Whiton Calkins (1863-1930). In A. N. O'Connell \& N. F. Russo (Eds.), Women in psychology: A bibliographical sourcebook (pp. 57-65). Westport, CT: Greenwood Press.

Furumoto, L. \& Scarborough, E. (1986). Placing women in the history of psychology: The first American women psychologists. American Psychologist, 41, 35-42. http://dx.doi.org/10.1037/0003-066X.41.1.35

Gergen, K. J. (1988). Feminist critique of science and the challenge of social epistemology. In. M. Gergen (Ed.), Feminist thought and the structure of knowledge (pp. 124-141). New York: University Press.

Gilbert, L.A. \& Osipow, S.H. (1991). Feminist contributions to counseling psychology. Psychology of Women Qurterly, 15, 537-547. http://dx.doi.org/10.1111/j.1471-6402.1991.tb00428.x

Gilligan, C. (1982). In a different voice: Psychological theory and women's development. Cambridge: Harvard University Press.

Hall, M., Kitzinger, C, Loulan, J., \& Perkins, R. (1992). The spoken word: Lesbian psychology, lesbian politics. Feminism and Psychology, 2 , 7-25. http://dx.doi.org/10.1177/0959353592021002

Harding, S. (1986). The science question in feminism. Ithaca: Cornell University Press.

Hare-Mustin, R.T., \& Marecek, J. (1990). Gender and the meaning of difference: Postmodernism and psychology. In R.T. Hare-Mustin \& J. Marecek (Eds.), Psychology and the construction of gender (pp. 22-64). New Haven: Yale University Press.

Hayes, S. C, Hayes, L. J., \& Reese, H. W. (1988). Finding the philosophical core: A review of Stephen C. Pepper's world hypotheses: A study in evidence. Journal of the Experimental Analysis of Behavior, 50, 97-111. http://dx.doi.org/10.1901/jeab.1988.50-97

Hollingworth, L.S. (1914). Variability as related to sex differences in achievement. American Journal of Sociology, 19, 510-530. http://dx.doi.org/10.1086/212287 


\section{B. F. SKINNER'S RADICAL BEHAVIORISM}

Hollingworth, L.S. (1916). Social devices for impelling women to bear and rear children. American Journal of Sociology, 22, 19-29. http://dx.doi.org/10.1086/212572

Iversen, I.H. (1992). Skinner's early research: From reflexology to operant conditioning. American Psychologist, 47, 1318-1328. http://dx.doi.org/10.1037/0003-066X.47.11.1318

Jacklin, C.N. \& McBride-Chang, C. (1991). The effects of feminist scholarship on developmental psychology. Psychology of Women Quarterly, 15, 549-556. http://dx.doi.org/10.1111/j.1471-6402.1991.tb00429.x

Kaschak, E. (1992). Engendered lives: A new psychology of women's experience. New York: Harper Collins.

Keller, E. F. (1985). Reflections on gender and science. New Haven, CT: Yale University Press.

Lerner, G. (1986). The creation of patriarchy. New York: Oxford University Press.

Lewin, M. \& Wild, C.L. (1991). The impact of the feminist critique on tests, assessment, and cognitive psychology. Psychology of Women Quarterly, 15, 581-596. http://dx.doi.org/10.1111/j.1471-6402.1991.tb00432.x

Lott, B. (1990). Dual nature of learned behavior: The challenge to feminist psychology. In R.T. Hare-Mustin \& J. Marecek (Eds.), Making a difference: Psychology and the construction of gender (pp. 65-101). New Haven, CT: Yale University Press.

Lott, B. (1991). Social psychology: Humanist roots and feminist future. Psychology of Women Quarterly, 15, 505-519. http://dx.doi.org/10.1111/j.1471-6402.1991.tb00426.x

Lott, B., \& Maluso, D, (1993). The social learning of gender. In A.E. Beall \& RJ. Sternberg (Eds.), The psychology of gender (pp. 99-123). New York: Guilford Press.

Marecek, J. \& Hare-Mustin, R.T. (1991). A short history of the future: Feminism and clinical psychology. Psychology of Women Quarterly, 15, p.521-536. http://dx.doi.org/10.1111/j.1471-6402.1991.tb00427.x

Morawski, J.G. (1990). Epistemology in psychology. In R.T. Hare-Mustin \& J. Marecek (Eds.), Psychology and the construction of gender (pp. 150-183). New Haven: Yale University Press.

Morawski, J.G. \& Agronik, G. (1991). A restive legacy: The history of feminist work in experimental and cognitive psychology. Psychology of Women Quarterly, 15, 567-579. http://dx.doi.org/10.1111/j.1471-6402.1991.tb00431.x

Morris, E. K. (1988). Contextualism: The world view of behavior analysis. Journal of Experimental Child Psychology, 46, 289-323. http://dx.doi.org/10.1016/0022-0965(88)90063-X

Morris, E. K. (1993a). Behavior analysis and mechanism: One is not the other. The Behavior Analyst, 16, 25-43.

Morris, E. K. (1993b). Mechanism and contextualism in behavior analysis: Just some observations. The Behavior Analyst, 6, 255-268.

O'Connell, A. N. \& Russo, N.F. (1991). Women's heritage in psychology: Past and present. Psychology of Women Quarterly, 15, 495-504. http://dx.doi.org/10.1111/j.1471-6402.1991.tb00425.x

O'Donnell, J.M. (1985). The origins of behaviorism: American psychology, 1870-1920. New York: New York University Press.

Palmer, D. C, \& Donahoe, J. W. (1992). Essentialism and selectionism in cognitive science and behavior analysis. American Psychologist, 47, 1344-1358. http://dx.doi.org/10.1037/0003-066X.47.11.1344

Pepper, S. C. (1942). World hypotheses: A study in evidence. Stanford, CA: Stanford University Press.

Russo, N.F. \& Denmark, F.L. (1987). Contributions of women to psychology. Annual Review of Psychology, 38, 279-298. http://dx.doi.org/10.1146/annurev.ps.38.020187.001431

Russo, N. F. \& O'Connell, A. N. (1980). Models from our past: Psychology's foremothers. Psychology of Women Quarterly, 5, 11-54. http://dx.doi.org/10.1111/j.1471-6402.1980.tb01032.x

Sherif, C.W. (1979). Bias in psychology. In J.A. Sherman \& E.T. Beck (Eds.), The prism of sex: Essays in the sociology of knowledge (pp.93-133). Madison, Wisconsin: University of Wisconsin Press.

Skinner, B.F. (1953). Science and human behavior. New York: Macmillan.

Skinner, B.F. (1957). Verbal behavior. New Jersey: Prentice-Hall.

Skinner, B.F. (1959). Cumulative record: A selection of papers. New York: Appleton-Century-Crofts.

Skinner, B.F. (1969). Contingencies of reinforcement-A theoretical analysis. New York: Appleton-Century-Crofts.

Skinner, B. F. (1971). Beyond freedom and dignity. New York: Alfred A. Knopf.

Skinner, B. F. (1974). About behaviorism. New York: Alfred A. Knopf.

Skinner, B.F. (1978). Reflections on behaviorism and society. New Jersey: Prentice Hall.

Skinner, B.F. (1984). (Reply to Staddon). Behavioral and brain sciences, 7, 707.

Thompson, H.B. (1906). The mental traits of sex. Chicago: University of Chicago Press.

Todd, J.T. \& Morris, E.K. (1983). Misconception and miseducation: Presentations of radical behaviorism in psychology textbooks. The Behavior Analyst, 6, 153-160.

Todd, J.T. \& Morris, E.K. (1992). Case histories in the great power of misrepresentation. American Psychologist, 47, 1441-1453. http://dx.doi.org/10.1037/0003-066X.47.11.1441

Travis, C.B., Gressley, D.L. \& Crumpler, CA. (1991). Feminist contributions to health psychology. Psychology of Women Quarterly, 15, 557-566. http://dx.doi.org/10.1111/j.1471-6402.1991.tb00430.x

Unger, R.K. (1983). Through the looking glass: No wonderland yet! (The reciprocal relationship between 


\section{RUIZ}

methodology and models of reality). Psychology of Women Quarterly, 8, 9-32. http://dx.doi.org/10.1111/j.1471-6402.1983.tb00614.x Unger, R.K. (1986). Looking toward the future by looking at the past: Social activism and social history.

Journal of Social Issues, 42, 215-227. http://dx.doi.org/10.1111/j.1540-4560.1986.tb00218.x

Unger, R.K. (1988). Psychological, feminist, and personal epistemology: Transcending contradiction. In.

M. McCanney Gergen (Ed.), Feminist thought and the structure of knowledge (pp. 124-141). New York: University Press.

Unger, R.K. (1989). Sex, gender, and epistemology. In M. Crawford \& M. Gentry (Eds.), Gender and thought (pp. 17-35). New York: Springer-Verlag.

Watson, J. B. (1913). Psychology as the behaviorist views it. Psychological Review, 20, 158-177. http://dx.doi.org/10.1037/h0074428

Watson, J. B. (1919). Psychology from the standpoint of a behaviorist. Philadelphia: Lippincott.

Watson, J. B. (1924) Behaviorism. New York: People's Institute.

Watson, J. B. (1927). The behaviorist looks at instincts. Harper's Monthly Magazine, 155, 228-235.

Watson, J. B. (1930). Behaviorism (rev. ed.). Chicago: University of Chicago Press.

Zuriff, G. E. (1985). Behaviorism: A conceptual reconstruction. Columbia University Press, New York. 